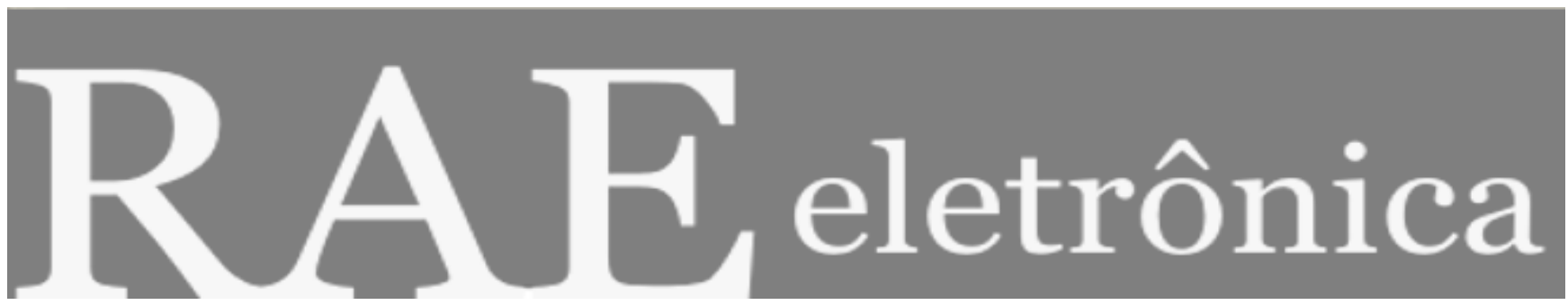

\title{
PERFIL DAS COMPETÊNCIAS EM EQUIPES DE PROJETOS
}

Por:

Roque Rabechini Junior

Marly Monteiro de Carvalho

RAE-eletrônica, Volume 2, Número 1, jan-jun/2003.

http://www.rae.com.br/eletronica/index.cfm?FuseAction=Artigo \&ID=1333\&Secao=OPERA/LOGI\&Volume=2\&Numero= $1 \& A n o=2003$

CCopyright, 2002, RAE-eletrônica. Todos os direitos, inclusive de tradução, são reservados. É permitido citar parte de artigos sem autorização prévia desde que seja identificada a fonte. A reprodução total de artigos é proibida. Os artigos só devem ser usados para uso pessoal e nãocomercial. Em caso de dúvidas, consulte a redação: redacao@,rae.com.br.

A RAE-eletrônica é a revista on-line da FGV-EAESP, totalmente aberta e criada com o objetivo de agilizar a veiculação de trabalhos inéditos. Lançada em janeiro de 2002, com perfil acadêmico, é dedicada a professores, pesquisadores e estudantes. Para mais informações consulte o site www.rae.com.br/eletronica.

RAE-eletrônica

ISSN 1676-5648

(C)2002 Editora: Fundação Getulio Vargas - Escola de Administração de Empresas de São Paulo.

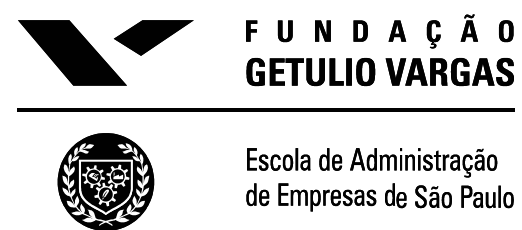




\title{
PERFIL DAS COMPETÊNCIAS EM EQUIPES DE PROJETOS
}

\section{Roque Rabechini Junior}

Engenheiro de Produção, Mestre em Administração pela FEA/USP. Doutorando pela Escola Politécnica da USP

e-mail: roquejr@usp.br

Endereço: Rua França Pinto, 820 / 94 São Paulo SP 04016-003

Interesses de pesquisa: Gerenciamento de Projetos

\section{Marly Monteiro de Carvalho}

Professora Doutora da Escola Politécnica da USP

e-mail: marlymc@usp.br

Endereço: Av. Prof. Almeida Prado, trav 2, nº 128 - Cidade Universitária - São Paulo, SP

Interesses de pesquisa: Estratégia, Gestão de Projeto e Gestão da Qualidade

\section{RESUMO}

A importância dos projetos na viabilização dos negócios tem crescido ultimamente e pode ser percebida pelo aumento do número de empresas que estão adotando a metodologia de gerenciamento de projetos (Kerzner, 2000). Para as empresas que buscam uma vantagem competitiva pela inovação, gerar competências na formação de equipes de trabalho passa a ser uma preocupação fundamental, bem como administrar múltiplas funções em diferentes perspectivas Frame, 1999).

(Com o intuito de apresentar um perfil das equipes, baseado em competências de gerenciamento de projetos, este artigo mostra o resultado de uma pesquisa realizada com 106 gerentes e técnicos de projeto de empresas de diversos setores. A análise pautou-se em aspectos relacionados à formação de competências em equipes de projetos, levando-se em conta duas orientações: a primeira focada na tarefa e resultados e a segunda nas pessoas.

\begin{abstract}
The relevance of project management has been increasingly studied. Different approaches can be found in the academic and practitioners bibliography, emphasizing the importance of project management and competencies' building to companies that looking for a competitive advantages by innovation. These companies need to acquire competencies to build project teams and to deal with multiple functions and different approaches (Frame, 1999).

The main purpose of this paper is to investigate the projects competencies management practices. The adopted methodological approach was a survey with 106 project manager and team members. The analysis was performed based on two major approaches: the first one is the project effectiveness and efficiency evaluation (tasks and results), and the second one is the team-oriented evaluation.
\end{abstract}

\section{Palavras-Chave}

Gerenciamento de Projeto; Formação de Equipes; Competências em Equipes; Equipe de Projetos; Gestão por Competências.

\section{KEY WORDS}

Project management; Team building; Teams competencies; Project’ Teams; Competence Profile. 


\section{INTRODUÇÃO}

No novo cenário competitivo delineado para o novo milênio, caracterizado pelo ritmo acelerado das mudanças tecnológicas e pela liberalização e volatilização dos mercados globais, as empresas sabem que para competir precisam aprender e gerar conhecimentos. As evidências já não são mais propriedades dos anais de congressos, aparecem agora, também, como notícias em revistas de negócios.

As empresas têm passado por um processo de transformação, organizando-se para poder dar respostas eficazes e rápidas, aos problemas ambientais, especialmente, aqueles que se referem à competição e posicionamento de mercado. Estas respostas são um conjunto de ações ou atividades que refletem a competência da empresa em aproveitar oportunidades, incluindo, portanto, sua capacidade de agir rapidamente, respeitando as limitações de tempo, custo e especificações.

Nesse sentido, cada vez mais os projetos tendem a crescer de importância e quanto mais alinhados estiverem às estratégias de negócios das empresas, certamente mais vantagens estas obterão na competição (King, 1993).

Investir na adoção de técnicas e ferramentas de gerenciamento de projetos está sendo uma das principais preocupações estratégicas nas diversas lideranças empresariais. Na década de 90, por exemplo, as práticas de gerenciamento de projetos se consolidaram como metodologia, sendo mencionada por diversos estudiosos, como disciplina obrigatória nas empresas que querem desenvolver e manter vantagens competitivas (Frame, 1999). A presença do Project Management Institute - PMI, em mais de cem países, atingindo a marca de 80 mil sócios individuais e cerca de 25 mil profissionais certificados no início do ano de 2002, é um indicador da preocupação crescente com esta temática.

Nos EUA, foi na década de 90 que os gastos em tecnologia de informação ultrapassaram os gastos em tecnologia de produção (Stwart,1997). A composição dos investimentos das empresas foi alterada, dada a valorização do capital humano.

Em síntese, na era do conhecimento o que mais adiciona valor aos produtos e serviços são as atividades inteligentes e não as rotineiras (Fleury e Fleury, 2000). Portanto, para conseguir resultados cada vez mais significativos torna-se importante o desenvolvimento e competências no âmbito do indivíduo e da organização.

Gerar competências em equipe é uma tarefa árdua, de longo prazo que exige recursos e diretrizes bem claras. $\mathrm{O}$ alinhamento entre as necessidades gerenciais e as competências das equipes de projetos deve ser almejado pelas empresas que querem participar de um mercado cada vez mais competitivo.

Com o intuito de melhor caracterizar as práticas de gerenciamento de projetos e, em especial, no que concerne às competências de equipes, este artigo mostra o resultado de uma pesquisa realizada com 106 gerentes e membros de equipes de projeto em empresas de diversos setores. Especial atenção será dada aos seguintes pontos: identificação dos aspectos relevantes para a formação de competências em equipes de projetos e apresentação de um quadro analítico que ajude membros de equipes de projetos a desenvolverem suas atividades.

\section{PROJETO: ASPECTOS CONCEITUAIS}

O conceito de projetos tem sido aprimorado nos últimos anos visando estabelecer um entendimento comum nas organizações que trabalham com este tipo de empreendimento. A norma ISO 10006 (1997), define projeto como sendo "um processo único, consistindo de um grupo de atividades 
coordenadas e controladas com datas para início e término, empreendido para alcance de um objetivo conforme requisitos específicos, incluindo limitações de tempo, custo e recursos".

Já para o PMI - Project Management Institute um projeto pode ser definido em termos de suas características distintivas, como sendo empreendimentos que requerem "empenhos temporários empreendidos para criar produtos ou serviços únicos" (PMBoK,2000). Assim, pode-se perceber dois conceitos intrínsecos desta definição: um referente à temporalidade, ou seja, todo projeto tem um começo e um fim bem determinado e outro que se refere à singularidade, ou seja, que o produto ou serviço é, de algum modo, diferente de todos os similares feitos anteriormente.

Para Sabbag (1999) o elemento empenho, desta definição se caracteriza como relevante pois "projetos envolvem complexidade com chances de falhas". $\mathrm{Na}$ decomposição destes conceitos o estudo de Sabbag (1999) propõe o modelo que denomina de Cubo da Incerteza onde são traçadas três variáveis: complexidade, singularidade e objetivos estreitos (rigorosos, limitados).

Este modelo avalia e propõe estratégias de gerenciamentos distintas para projetos. Segundo Sabbag (1999) "projetos diferentes resultam em cubos diferentes. Por exemplo, um projeto de construção de uma estrada ou uma construção típica, normalmente apresenta alta estreiteza em relação aos objetivos, mas baixa complexidade e singularidade". Por outro lado "um típico projeto de Pesquisa e Desenvolvimento ou de desenvolvimento de um novo software, ao contrário, podem se mostrar com alta unicidade e complexidade, mas envolvendo baixa estreiteza de objetivos"

O gerenciamento de projetos definido na norma ISO 10006 (1997) "inclui o planejamento, organização, supervisão e controle de todos os aspectos do projeto, em um processo contínuo, para alcançar seus objetivos". Para o PMBoK (2000), gerenciamento de projetos significa "aplicação do conhecimento, habilidades, ferramentas e técnicas `as atividades do projeto a fim de atender ou superar as necessidades e expectativas que os interessados (stakeholders) possuem no projeto:" Neste sentido, atender ou superar as necessidades e expectativas das partes interessadas requer o equilíbrio das exigências impostas pelos seguintes itens: a) escopo, tempo, custo e qualidade; b) partes interessadas com necessidades e expectativas diferentes; c) exigências identificadas (necessidades) e exigências não identificadas (expectativas).

O processo de gerenciamento de projetos nas empresas requer aprimoramento de administração de nove áreas de conhecimento (PMBoK, 2000). Estas áreas se referem à integração dos diversos elementos-chave de um projeto alguns essenciais, outros facilitadores, quais sejam: integração, escopo, prazos, custos, recursos humanos, aquisições, qualidade, riscos, comunicação do empreendimento.

O PMBoK (2000) em seu capítulo dedicado ao gerenciamento dos recursos humanos, propõe processos necessários para fazer o uso mais efetivo das pessoas envolvidas com o projeto. Assim, o desenvolvimento das competências relacionadas ao projeto se faz importante e administrá-las se torna essencial para seu sucesso. Segundo Verma (1995) as pessoas formando um time (equipe) representam o centro deste sucesso no caso do gerenciamento de projetos. Verma (1995) ainda, enfatiza a existência de diferenças nítidas entre grupos de indivíduos e equipes de projetos, considerando-se o dinamismo, seus papéis, nível de comprometimento, autoridade e relação entre os membros.

Estas diferenças apontam para uma necessidade maior: entender as diversas nuances da competência em gerenciamento de projetos. 


\section{COMPETÊNCIAS: SÍNTESE DA DISCUSSÃO TEÓRICA}

A palavra competência vem do latim, competere. O conceito de competências pode ser visto, inicialmente com a decomposição da palavra em latim: com, cujo significado é conjunto e petere, cujo significado é esforço.

As competências empresariais foram exaustivamente estudadas por Hamel \& Prahalad (1995), quando estabeleceram o conceito de competências essenciais. Para eles competência "é um conjunto de habilidades e tecnologias, e não uma única habilidade ou tecnologia isolada". Para caracterizar uma competência essencial três elementos são considerados: o valor percebido pelo cliente; a diferenciação frente aos concorrentes e a capacidade de expansão. $O$ primeiro refere-se às habilidades que permitem a empresa oferecer um benefício fundamental ao cliente, o segundo a uma capacidade única e o terceiro a possibilidade de geração de uma gama de novos produtos, como elementos de diferenciação competitiva. Assim, competência essencial é uma fonte de vantagem competitiva.

Ainda segundo Hamel \& Prahalad (1995), existem vários níveis de competição, dado pela competência essencial. As organizações que visam competir pelo desenvolvimento de competências têm como meta no primeiro nível a aquisição ou desenvolvimento de habilidades ou tecnologias. No segundo nível buscam sintetizar suas competências e, no terceiro visam maximizar a fatia do produto essencial da organização.

Para Fleury \& Fleury, (1999) a competência do indivíduo pode ser entendida segundo três eixos fundamentais: pela pessoa, por sua formação educacional e por sua experiência profissional. Esta integração entre a competência no âmbito individual e da organização que permitem a agregação de valor social e econômico. Os autores definem competências com: "um saber agir responsável e reconhecido, implicando em mobilizar, integrar, transferir conhecimentos, recursos, habilidades, que agregue valor econômico à organização, e valor social ao indivíduo", conforme ilustrado na Figura 1.

Figura 1 - Competências como fonte de valor para o indivíduo e para a organização.

Fonte: Fleury \& Fleury (2000)

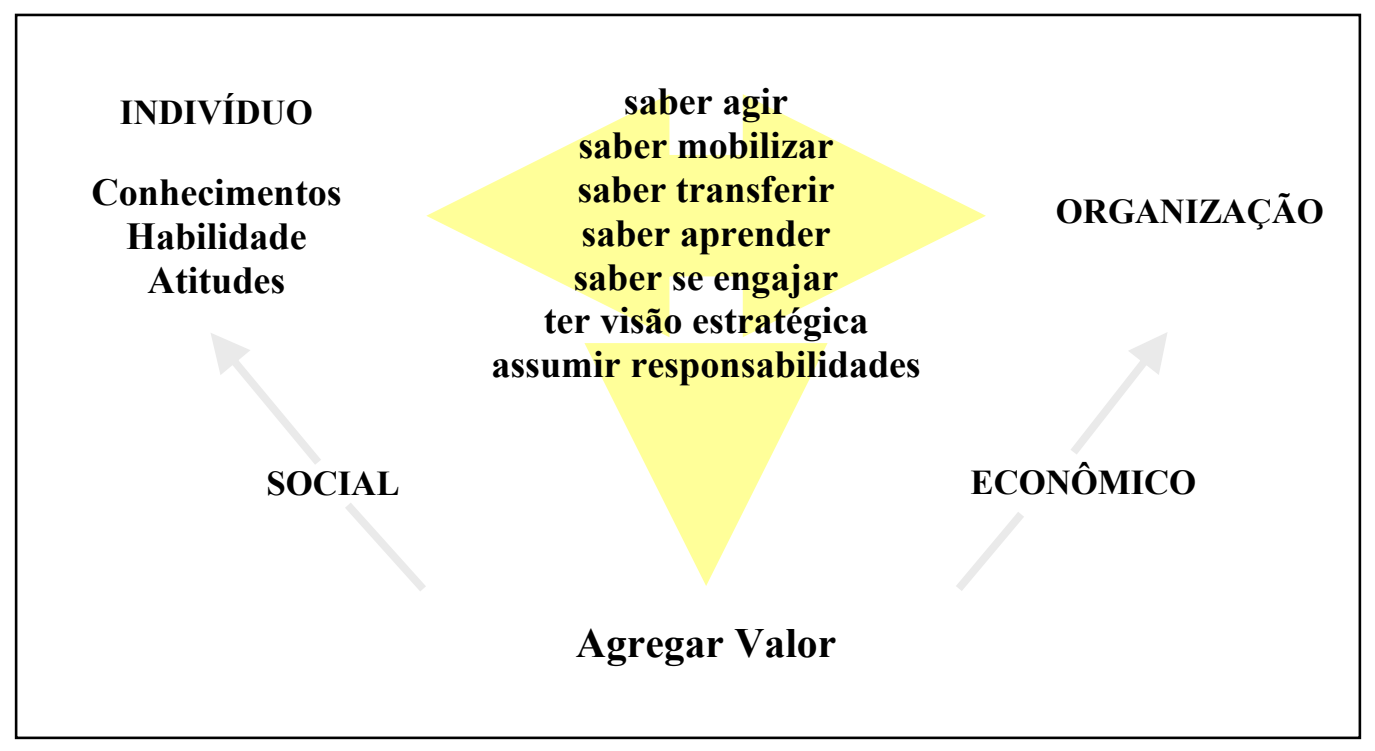


As competências organizacionais, por seu lado, se referem à possibilidade de indivíduos ou equipes a conduzirem seus projetos de forma a alcançarem os objetivos propostos, dando maior competitividade às empresas.

As competências também foram estudadas por Hartman \& Skulmoski (1999) que, associaram ao seu conceito à existência de um conhecimento especial. Aprimorando esta visão e vinculando-a aos resultados de uma empresa ou projeto, estes autores apontam para o fato de que as competências fazem parte de um grupo de conhecimento, habilidades e atitudes que influenciam o desempenho de um projeto. Expandindo este conceito, então, tem-se que competências são características que dão desempenho superior a um projeto.

\section{Abordagem de CompetênCias no contexto do Gerenciamento de Projetos}

Frame (1999) sugere três tipos de competências em gerenciamento de projetos: as individuais, as de equipe e, as da empresa. As primeiras se referem às aptidões e habilidades dos indivíduos na solução de problemas. As competências da equipe, por sua vez se relacionam com a capacidade de resolução de problemas complexos em contexto multidisciplinar. Finalmente, as competências da empresa se referem a sua capacidade de criação de um ambiente que possibilite o envolvimento tanto do indivíduo quanto das equipes, a tocarem seus projetos de forma eficaz.

\section{Competências Individuais no contexto do Gerenciamento de Projetos}

As competências individuais podem ser abordadas segundo o modelo de stakeholders (indivíduos que afetam ou são afetados pelos resultados do projeto) proposto por Cleland (1988) que, em linhas gerais, agrupou-os em: primários e secundários. Os stakeholders primários são representados por indivíduos que via de regra são os mais visíveis em projetos, como: o gerente de projeto, o patrocinador, o pessoal técnico, o gerente funcional e de suporte. Já os secundários em geral dependem do âmbito e abrangência do projeto, podendo envolver o governo, subcontratadas etc.

Do grupo de stakeholders primários o elemento mais conhecido, é sem dúvida o gerente de projetos. Estudos recentes que enfatizam a importância do gerente de projetos foram feitos por Rabechini Jr (2001) e Rabechini Jr; Carvalho (1999), em que são discutidas suas relevantes habilidades sob duas óticas distintas: a dos membros da equipe e a do próprio gerente de projeto.

Considerando-se o modelo de habilidades proposto por Sthub et all (1994), Rabechini Jr (2001) verificou a convergência de gerente e equipe nas questões referentes à liderança, facilidade de negociação e capacitação técnica. Não obstante, os quesitos relacionamento com o cliente, comunicação e orçamento apresentaram óticas distintas, realçando a lacuna entre as visões de competências gerenciais dadas pelos gerentes e técnicos.

Um outro elemento muito importante que merece destaque entre os stakeholders primários, é a figura do patrocinador. Em geral, os patrocinadores devem proporcionar um ambiente adequado para que o projeto atinja os resultados esperados, provendo-os de recursos. Para Dinsmore (1999) o patrocinador é uma espécie de "anjo da guarda" do projeto e de seu gerente, em que exerce a função de "supervisionar e proteger ambos do risco de impactos negativos potenciais". As competências de um patrocinador variam conforme a tradição da empresa, a natureza do projeto e dos estilos gerenciais adotados, podendo ser agrupadas conforme a fase do ciclo de vida do projeto, conforme Tabela 1. 
Tabela 1 - Competências do Patrocinador, Adaptado de Dinsmore (1999)

\begin{tabular}{|l|r|r|}
\hline Fases do Ciclo de Vida & Características \\
\hline Desde o início do Projeto & $\checkmark$ Assegurar que as estratégias, planos e controles do projeto estejam estabelecidos; \\
& $\checkmark$ Fornecer apoio para a mobilização da equipe de projeto; \\
& $\checkmark$ Assegurar que o projeto seja adequadamente iniciado e que as iniciativas de \\
& $\checkmark$ trabalho em equipe sejam tomadas; \\
& $\checkmark$ Fornecer apoio político para o projeto no nível executivo e, \\
& $\checkmark$ Orientar o gerente do projeto conforme o necessário. \\
\hline À medida que o projeto se & $\checkmark \checkmark$ Participar nas avaliações formais e periódicas do projeto; \\
desenvolve & $\checkmark$ Estar disponível para apoio e consultas; \\
& $\checkmark$ Acompanhar os relatórios de progresso do projeto e, \\
& $\checkmark$ Envolver-se se o projeto sair de seu curso. \\
\hline Quando o projeto está chegando & $\checkmark$ Monitorar a transição projeto-operação; \\
próximo ao fim & $\checkmark$ Estimular um rápido o encerramento do projeto e, \\
& $\checkmark$ Assegurar a documentação das lições aprendidas". \\
\hline
\end{tabular}

Outro elemento muito importante neste exame dos stakeholders primários é constituído pelo pessoal técnico, responsável pelo desenvolvimento dos produtos ou serviço do projeto, sejam eles considerados intermediários ou final. Normalmente suas competências referem-se ao conteúdo técnico do projeto.

Finalmente, fazem parte deste grupo, os gerentes funcionais. São eles os responsáveis por gerenciar os recursos a serem empregados no projeto. Cabe a eles, também, discernir a distribuição destes recursos de acordo com as estratégias declaradas da empresa. Entender o alinhamento entre projetos e estratégias é uma de suas competências básicas.

\section{Competências em Equipes de Projeto}

O gerenciamento das equipes de projeto não é uma tarefa fácil, por dois motivos: o primeiro é que os times de projetos são extremamente dinâmicos, os membros do grupo estão em constante mudança; o segundo é que talvez somente o gerente do projeto e alguns membros da alta gerência conseguem ver a equipe do projeto como uma entidade única. Se os gerentes de projeto desejam um grupo motivado eles devem trabalhar nesta direção. Isto é possível através da condução de reuniões produtivas, da criação de um espaço físico próprio para o grupo, da criação de sinais específicos do grupo, da divulgação dos resultados do grupo, do desenvolvimento de reconhecimento de esforços especiais, do desenvolvimento, por parte do gerente de projeto, de um comportamento voltado às pessoas do seu grupo e de uma correta estruturação do grupo quanto às responsabilidades de cada membro do mesmo. (Frame, 1994).

Verma (1995) explicita diferenças distintivas entre grupos de indivíduos e membros de equipes de projetos. Enquanto os grupos são formados por membros independentes com participação parcial nas tarefas de forma individual, as equipes prezam a interdependência, com participação ativa e coletiva nas atividades de projetos. Neste sentido o desenvolvimento de equipes faz-se necessário através de um processo contínuo de gerenciamento, medindo-se seu desempenho ao longo do projeto.

Para Thamhain (1993), formação de equipes pode ser definida como "um processo que agrega um conjunto de indivíduos com diferentes necessidades, habilidades e inteligências e transforma-os numa unidade de trabalho eficaz e integrada. Neste processo de transformação os objetivos e energias individuais se misturam, dando suporte aos objetivos da equipe". Partindo deste conceito, Thamhain (1993), analisou o desempenho de equipes de projetos, considerando as facilidades e barreiras, os fatores ambientais e estilos de liderança gerencial para sua formação e desenvolvimento. Estas 
variáveis compõem-se em dois grupos (clusters) distintos de indicadores que podem ser utilizados para estabelecer as bases para identificar as competências em equipes de projetos bem como medir seu desempenho. O primeiro cluster é formado por elementos com características orientadas as atividades e resultados em projeto, o segundo, orientado as pessoas.

Estes clusters de indicadores estão apresentados na Tabela 2, destacando-se seus principais aspectos.

Tabela 2 - Indicadores de Desempenho de Tarefas e Pessoas (Fonte: Thamhain; 1993)

\section{\begin{tabular}{|l|l|}
\hline Indicadores de Tarefa & Indicadores de Pessoas
\end{tabular}}

Desempenho técnico: indicador que visa medir o Envolvimento da equipe: referem-se aos stakeholders e com o aprimoramento técnico de seus membros e, via de resultado do projeto em si. A equipe deve ser pró-ativa e passar regra, avaliar a equipe por seu desempenho técnico

essa imagem aos envolvidos do projeto, gerando um ambiente de confiança;

Planejamento dos prazos e orçamentos: indicadores que medem a capacidade da equipe em gerenciar os prazos e custos do projeto;
Gerenciamento de conflitos: refere-se ao processo de identificação de conflitos e seus modos de resolução. Toda equipe de projetos passa por momentos de conflito que devem ser administrados, para evitar que o desempenho diminua. Neste sentido, identificar e antever possíveis pontos de conflitos, resolvendo-os antes que eles aconteçam é um bom procedimento da equipe;

Avaliação por resultados: são os fatores relacionados aos alvos que o projeto precisa atingir e, também das recompensas envolvidas quando atingidos;

Comunicação: é um indicador fundamental para que uma equipe obtenha alto desempenho. O conhecimento do plano do projeto e o processo de geração, estoque, disseminação e controle das informações são aspectos críticos do gerenciamento;

Inovadoras e criatividade: considerando o ambiente, Espírito de equipe: As equipes consolidadas geralmente têm estes indicadores representam a valorização da membros que apresentam espírito colaborador em detrimento do criatividade de seus membros e das soluções de fato individualismo, buscam juntos os resultados e procuram sempre se entendidas como criativas;

proteger contra eventuais injustiças;

Estabelecimento de especificações: são indicadores que se referem aos requisitos do projeto e controles periódicos da qualidade das atividades do projeto até a hora do aceite do cliente;

Gerenciamento das mudanças: indicam a flexibilidade e o acompanhamento do processo de implementação e,

Previsões de prazo e custo: indicam o entendimento das tendências do projeto bem como estabelecimento de cenários dos negócios da organização ao qual o projeto está vinculado

Confiança mútua: A confiança aqui discutida refere-se a um dos pré-requisitos para a formação de equipe, pois uma atividade tem interface com informações e resultados oriundos de outras atividades, a equipe precisa ter a confiança que tais entradas estejam de acordo com os requisitos planejados;

Auto-desenvolvimento: Os membros de uma equipe buscam desenvolver habilidades, que irão contribuir para se atingir os resultados do projeto, identificando possibilidades técnicas para isto. A participação em congressos e simpósios que formem competências visando a melhoria dos resultados do projeto é importante

Interface organizacional: refere-se a capacidade da equipe em se relacionar com a empresa visando conseguir recursos e apoios para o projeto e,

Capacidade da equipe em buscar resultados do projeto e se relacionar com a empresa: Quanto mais a equipe conhece as potencialidades e possibilidades da empresa que faz parte, poder explorar melhor seus recursos e, certamente, melhor contribuir para o sucesso de seus projetos

O cluster de indicadores orientados ao desempenho de equipes relacionados às tarefas visa apontar a contribuição funcional que a equipe dá ao projeto. Archibald (1983) descreve estas funções que devem ser desempenhadas durante todo o ciclo de vida do projeto pelo gerente e por membros da equipe. São elas: 
$\checkmark$ Gerenciamento das atividades e do próprio projeto;

$\checkmark$ Desenho e desenvolvimento do produto;

$\checkmark$ Manufatura do projeto;

$\checkmark$ Procura (compra) e subcontratações;

$\checkmark$ Teste e Instalação do produto do projeto.

Além do mais, Archibald (1993), recomenda determinadas categorias de pessoas chaves (por exemplo, gerente de projeto, engenheiro de projeto, administrador de contratos, coordenador de manufatura, entre outros) que devem fazer parte de uma equipe de projetos associando-as as funções.

Para desempenhar estas funções, gerentes de projetos e membros de equipes devem estar orientados na: busca de resultados, no planejamento e acompanhamento de prazos e custos, no estabelecimento de especificações, gerenciamento de escopo e mudanças, etc.

Tudo isto indica que, de certa forma, estas funções estão correlacionadas ao cluster de indicadores de tarefas proposto no modelo de Thamhain (1993). Sua medida, em geral refere-se diretamente ao desempenho do projeto.

No entanto, uma equipe de alto desempenho se desenvolve desempenhando também funções relacionadas às questões pessoais. Neste aspecto cabe lembrar dos modelos de competências muito discutidos atualmente, explorando naturalmente o âmbito dos relacionamentos e atitudes.

No modelo de Thamhain (1993) para caracterizar uma equipe, os indicadores foram identificados considerando-se o ambiente em que a equipe de projetos opera e suas facilidades e barreiras de formação. Em geral estes indicadores são medidos indiretamente acerca do desempenho do projeto.

A Figura 2 mostra um quadro referencial que servirá de base para análise destes dois grupos de indicadores, com base no modelo simplificado de caracterização de equipes.

Figura 2 - Modelo Caracterização Equipes (adaptado de Thamhain; 1993).

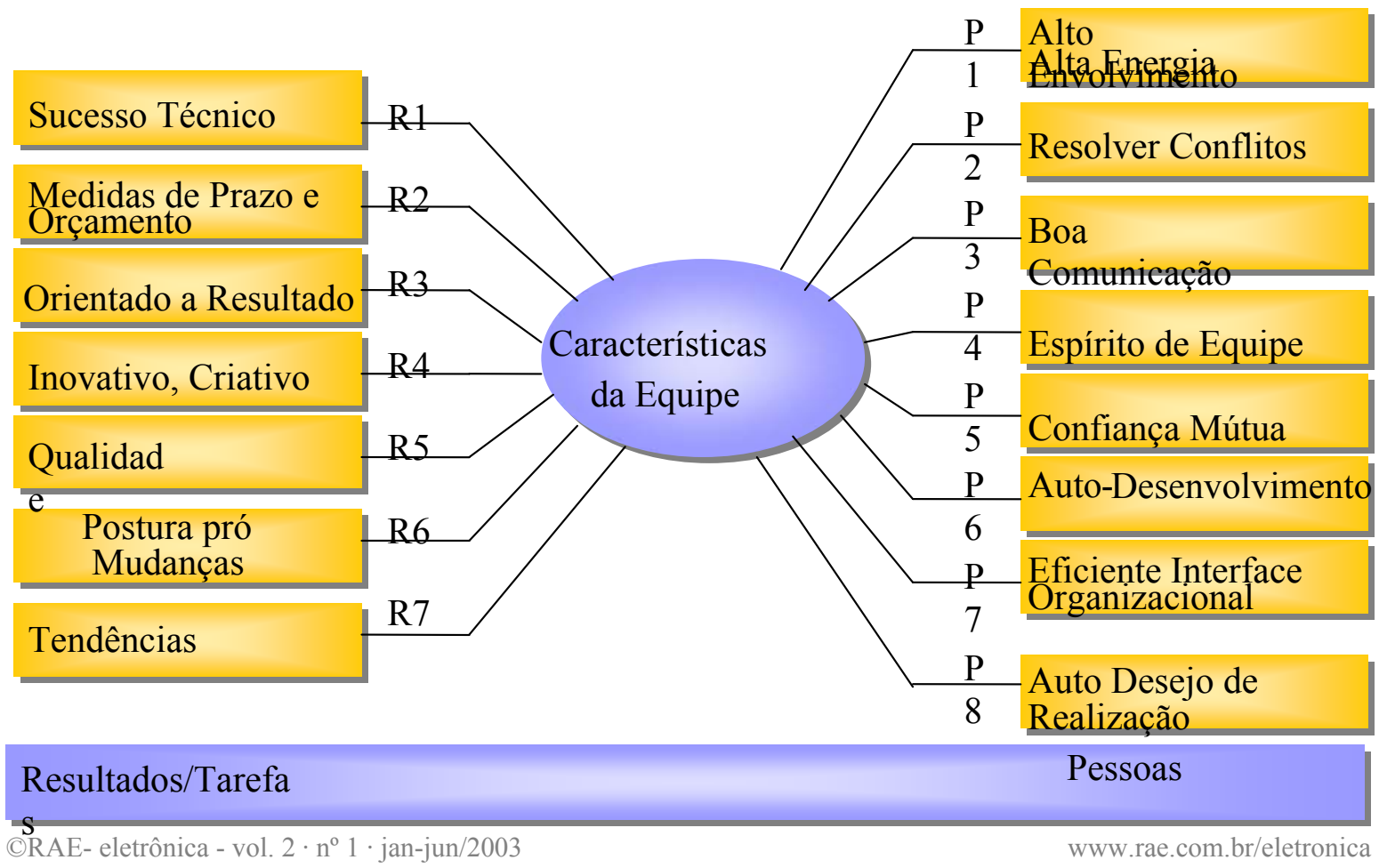


As competências da equipe de projeto se referem à possibilidade de indivíduos trabalharem em conjunto visando atingir os objetivos do projeto. As vantagens de se trabalhar equipe é que as competências funcionais podem ser agrupadas e orientadas para um mesmo objetivo.

A estrutura de uma equipe está fortemente ligada a estrutura organizacional a qual ela faz parte e seu desempenho pode ser sensível a esta estrutura. No entanto, para medir o desempenho de uma equipe é necessário considerar alguns critérios mínimos, segundo Frame (1999). Boas equipes têm as seguintes características: objetivos factíveis e claros; subprodutos intermediários (deliverables) bem definidos; conjunto de habilidades gerencial e técnica diferenciadas; nível de educação entre os membros da equipe; uso de ferramentas adequadas para o trabalho; disciplina; coesão; liderança; estrutura apropriada e habilidades para integração visando buscar resultados e se relacionar bem com clientes.

\section{Competências Organizacionais no contexto do Gerenciamento de Projetos}

As competências organizacionais, por seu lado, se referem à possibilidade de indivíduos ou equipes a conduzirem seus projetos de forma a alcançarem os objetivos propostos, dando maior competitividade às empresas.

Kerzner (2000) elaborou um modelo evolutivo de maturidade em gerenciamento de projetos em uma empresa, composto de cinco fases de um ciclo de vida genérico, quais sejam: embrionária; reconhecimento da alta administração; reconhecimento da média gerência; crescimento e maturidade. A Figura 3 ilustra o modelo.

Figura 3 - Ciclo de Vida em Gerenciamento de Projetos. (Kerzner; 2000).

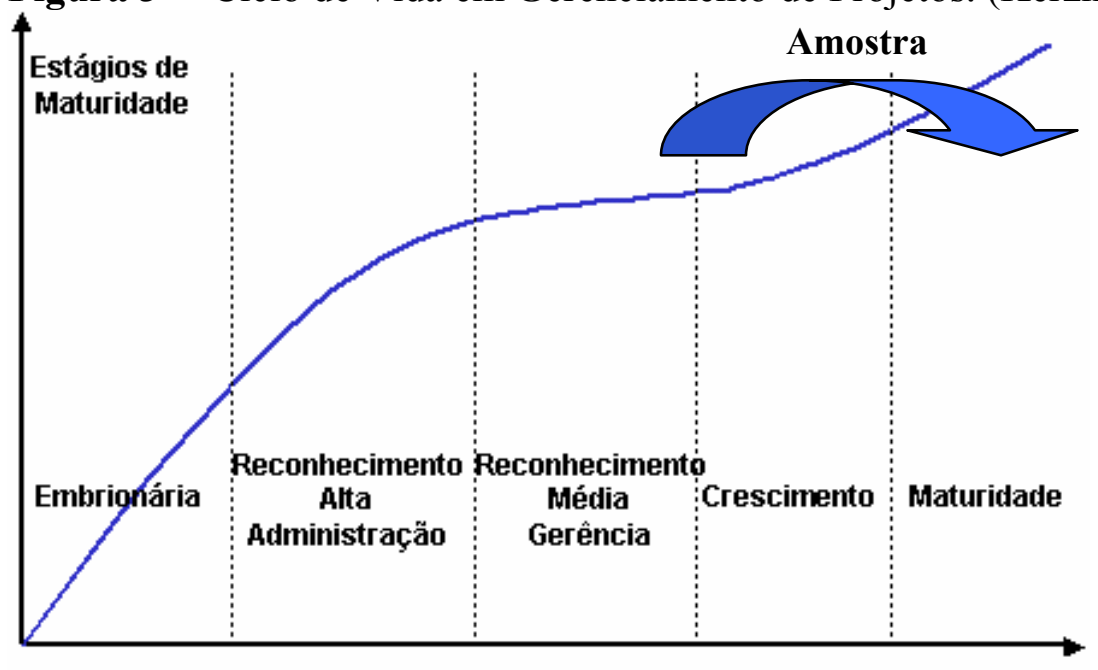

Fases do Ciclo de Vida

As principais características da fase embrionária referem-se ao reconhecimento da importância do gerenciamento de projetos para a empresa. De forma geral, as empresas reconhecem os benefícios do gerenciamento de projetos através de suas aplicações, necessidades e do quê precisa ser feito.

O reconhecimento da importância do gerenciamento de projetos pela alta administração, pode ser percebido pelos seguintes pontos: visibilidade em termos de suporte; entendimento da disciplina 
gerenciamento de projetos; estabelecimento de patrocinador no nível executivo e postura favorável na mudança da forma de fazer negócios.

As principais características da terceira fase se referem à gerência de linha. Neste sentido é necessário que o suporte vindo da gerência de linha seja explicito. Também é necessário que este nível gerencial esteja comprometido na busca do uso do gerenciamento de projetos. Isto significa, entre outras ações, buscar educação para tal fim.

A fase de crescimento é caracterizada pelo desenvolvimento de uma metodologia de gerenciamento de projetos pela empresa. Destaca-se nesta fase a importância dada ao comprometimento com atividades de planejamento.

A última fase, a de maturidade, refere-se ao desenvolvimento de um sistema formal de controle gerencial que integre custos e prazos, além do desenvolvimento de um programa educacional com o intuito de aumentar as competências em gerenciamento de projetos na empresa.

Não obstante, a fase de maturidade não significa a excelência em gerenciamento de projetos. Kerzner (2000) advoga que para atingir o patamar de excelência em gerenciamento de projetos as organizações precisam criar um ambiente em que os projetos alcançam sucesso continuamente, estabelecendo processos integrados, suporte gerencial adequado, excelência comportamental, informalidade, postura de treinamento e educação e, finalmente, criando uma cultura em gerenciamento de projetos.

As competências no âmbito da empresa também foram estudadas por Frame (1999), cujo modelo de formação de competências em gerenciamento de projetos evidencia sete elementos: procedimentos claros e bem formulados; acesso à informação; recursos humanos e materiais com quantidade e qualidade suficiente; oportunidades para treinamento; visão clara dos objetivos da empresa; cultura para melhoria contínua e, institucionalização do gerenciamento de projetos.

\section{Aspectos Metodológicos}

Com o objetivo de melhor mapear e caracterizar as práticas de gerenciamento de projetos, em especial no que concerne às competências de equipes de projetos, foi elaborada uma pesquisa com gerentes de projetos de empresas de diferentes setores.

Para atingir os objetivos propostos neste trabalho, inicialmente elaborou-se uma revisão bibliográfica sobre gestão de empreendimento com ênfase na gestão de equipes. Esta revisão pautou-se na identificação de um modelo visando dar sustentação teórica no que concerne ao interesse dos autores: caracterização de equipes em projetos.

Em seguida, foi desenvolvido um instrumento de pesquisa baseado nos modelos de formação de competências em equipes de projetos e de maturidade, propostos por Thamhain (1993) e Kerzner (2000), respectivamente.

O instrumento de pesquisa proposto foi um questionário fechado composto, basicamente, por três seções. Na primeira seção estão os dados de caracterização da amostra, tanto no que concerne ao entrevistado como a empresa, quais sejam: nome, sexo, idade, experiência em projetos e cargo, o ramo de atividade da empresa e faturamento. Na segunda seção foram agrupados os dados referentes às competências organizacionais e à atividade de gerenciamento de projetos, conforme proposto por 
Kerzner (2000). A última, e mais extensa seção, destinou-se às questões sobre competências em equipes de projeto, com base no proposto por Thamhain (1993).

As questões sobre a prática da gerência de projetos na empresa, pautadas no modelo de maturidade, contemplaram os seguintes pontos: estrutura para gerenciar projetos; definição da carreira do gerente de projetos, metodologia descrita e padronizada, sistema formal de controle gerencial, programa educacional em gerenciamento de projeto, relevância do gerenciamento de projetos e comprometimento (a empresa; a alta gerência; e a gerência funcional).

Conforme proposto pelo modelo de Thamhain (1993), a última seção incluía clusters de indicadores orientados aos resultados de projeto e aqueles orientados às pessoas. No primeiro cluster foram abordados aspectos como: desempenho técnico, parâmetros de prazos e orçamentos, resultados, ambiente de inovação, qualidade, mudanças e tendências. No segundo cluster, as variáveis orientadas às pessoas, questionou-se: envolvimento da equipe, resolução de conflitos, capacidade de comunicação, espírito de equipe, confiança, autodesenvolvimento, interface organizacional e capacidade de equipe em buscar resultados unida.

As opiniões dos entrevistados puderam então ser registradas utilizando-se uma escala do tipo da de Likert, variando de 1 a 7, sendo que 1 correspondeu a "não concordo" e 7 correspondeu a "concordo plenamente".

Seleção das empresas que compuseram a amostra foi feita de forma aleatória, no entanto, a identificação dos respondentes foi teve viés, pois se escolheu aqueles funcionários que tinham experiência como gerentes de projetos e técnicos (membros de equipes).

Este questionário foi aplicado a uma amostra de 106 entrevistados, todos trabalhando diretamente com projetos e a maioria gerentes de projetos.

\section{Caracterização da Amostra}

Dos entrevistados que compuseram a amostra, 52\% têm menos que 35 anos, 40\% estão distribuídos na faixa dos 35 anos aos 45 anos e, 8\% têm mais que 45 anos. Predominam os homens $(76 \%)$.

Quanto à carreira pode-se dizer que a maioria dos entrevistados, $(84 \%)$, têm mais que 10 anos de experiência profissional e que $76 \%$ desempenham funções gerenciais.

Merecem destaques os setores de Tecnologia de Informação (35\%), Consultoria e Engenharia (18\%) e Indústria Mecânica e Eletrônica (17\%), na composição da amostra, conforme ilustra a Figura 4. 
Figura 4 - Ramo de Atividade

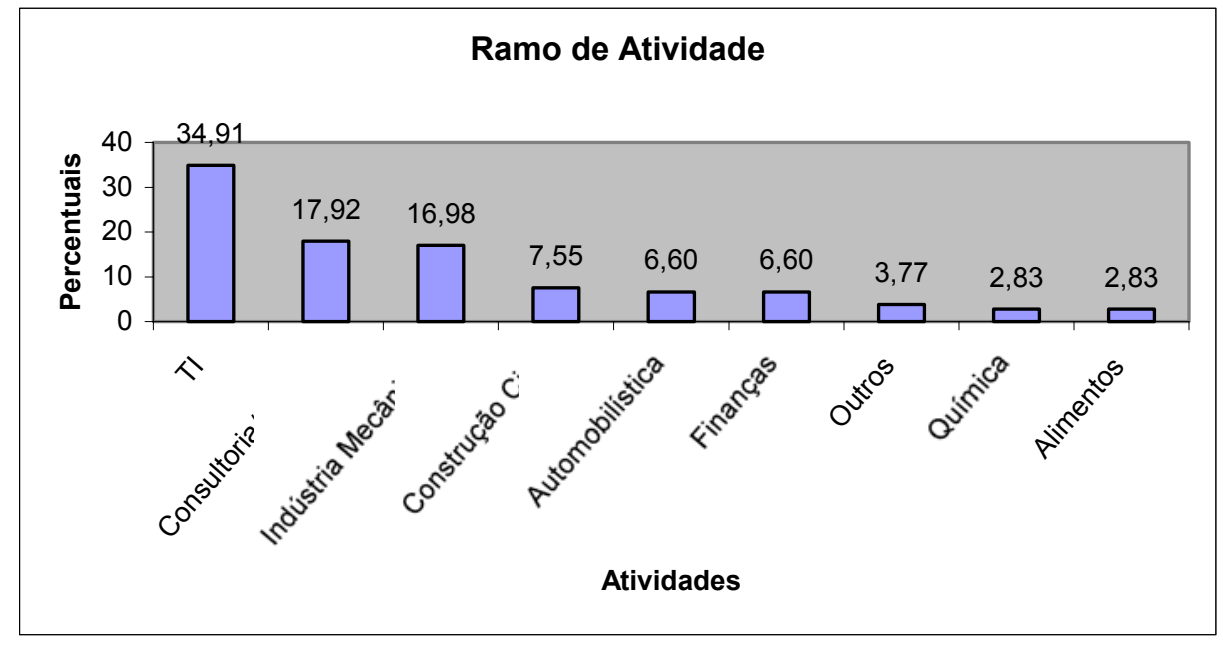

\section{Resultados da Pesquisa: Competências em Equipes de Projetos: Resultados}

O instrumento de pesquisa foi planejado de forma a permitir a tabulação dos resultados em indicadores de tarefa e de pessoas, conforme se apresenta a seguir.

\section{Indicadores de Tarefa}

As notas obtidas referentes aos indicadores de tarefa se concentraram numa faixa entre 4.54 a 5.50 da escala de Likert, conforme mostra a Figura 5, com média $(4,96)$.

Figura 5 - Indicadores de Tarefa

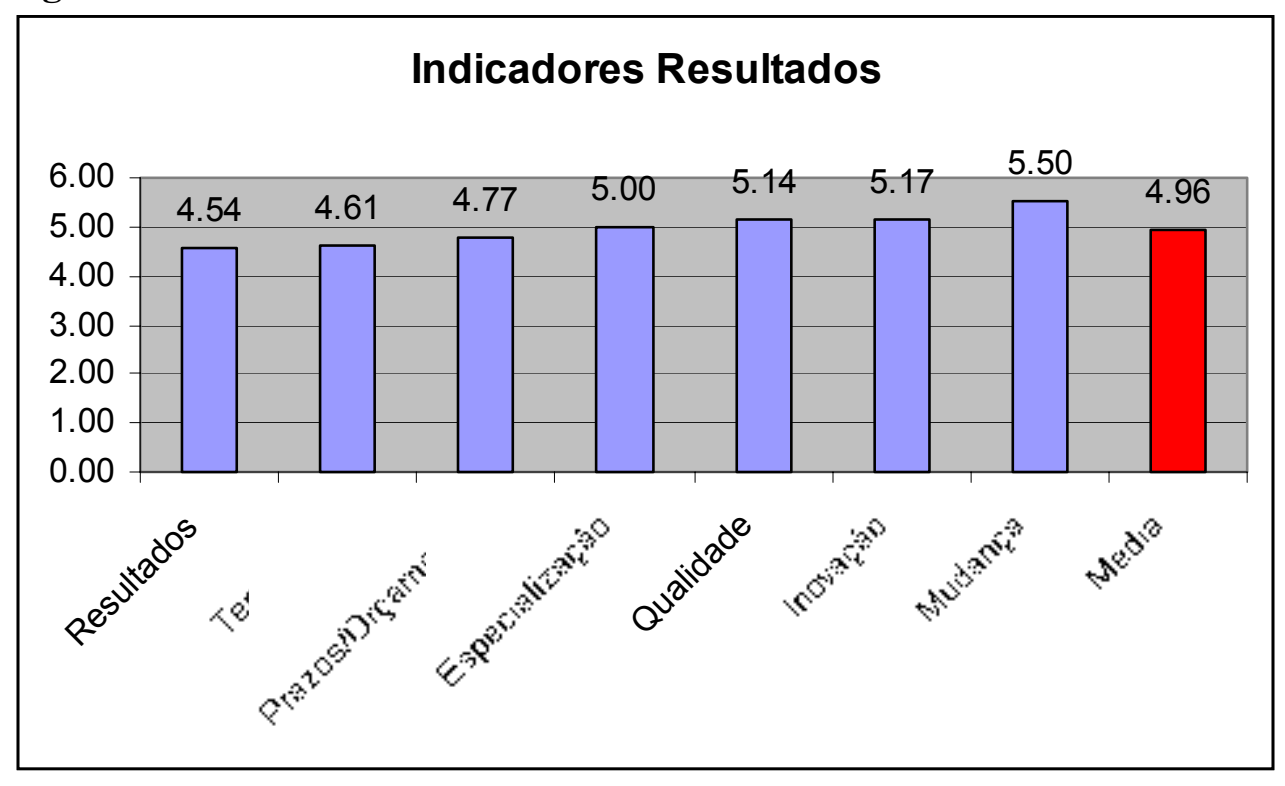

Como é possível notar, o indicador que se refere ao gerenciamento de mudanças, foi percebido como o de maior grau de importância $(5,50)$ pelos entrevistados. A demanda por flexibilidade em projetos que as equipes recebem e a necessidade de incorporarem estas mudanças rapidamente são as principais razões da ponderação obtida neste quesito. 
Por outro lado, o indicador de tarefa de menor grau foi verificado em relação aos objetivos do projeto e seus resultados. Este indicador está relacionado aos alvos que o projeto precisa atingir e mostra que, as equipes da amostra, têm pouca clareza quanto aos objetivos do projeto e também das recompensas envolvidas quando atingidos. O baixo grau obtido em relação aos demais indicadores pode mostrar, conforme verificou Sabbag (1999) que, quando os objetivos são muitos "estreitos", e assim foram percebidos pelas equipes deste trabalho, mais difícil será obter sucesso no projeto, pois neste cenário criam-se mais condições de incertezas.

Em relação à capacidade de prever tendências e administrar eficientemente os prazos e custos do projeto as equipes obtiveram graus de importância, 4,61 e 4,77, respectivamente. Neste sentido, podese verificar que as equipes dispensam pouco esforço no planejamento e controle de prazos e custos, sem enfatizar o uso de ferramentas de previsão de tendência e mesmo sem se preocupar com o controle efetivo do projeto. Olhando estas notas sob a perspectiva de Kerzner (2000), nota-se a imaturidade das equipes envolvidas. $\mathrm{O}$ uso de processo comum, o que demonstra que a metodologia de gerenciamento de projetos ainda não está madura, conforme Kerzner (2000).

Os outros três indicadores - especialização, qualidade e inovação - receberam os seguintes graus, respectivamente: 5,00; 5,14 e 5,17. Estes valores, superiores as preocupações relativas aos custos e prazos, pode ser um indício que os projetos apresentam alguma complexidade e singularidade segundo o Cubo da Incerteza (Sabbag;1999), o que pode ser explicado pela predominância de projetos de TI na amostra estudada.

\section{Indicadores de Pessoal}

Os indicadores referente as características orientadas as pessoas foram avaliados e também se concentraram numa faixa entre 4.72 a 5.52, conforme mostra a Figura 6.

Figura 6 - Indicadores Pessoais

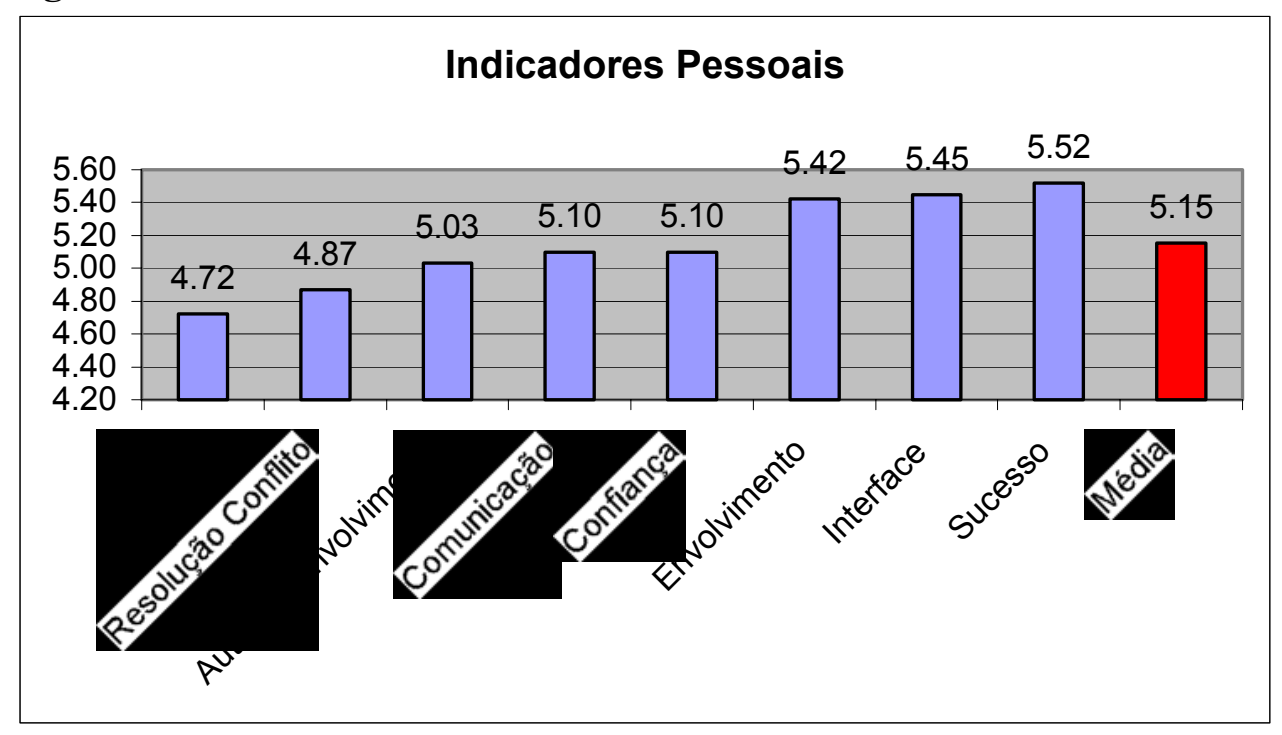

Os dados da amostra revelam que as equipes referenciadas mostram-se motivadas para conseguir os resultados, uma vez que a média obtida sobre estes aspectos foi relativamente alta $(5,52)$. Acreditase, então, que para atingir resultados elas conseguem se envolver com a organização de forma eficiente 
$(5,45)$, ou seja, conhecem a organização e são por ela é conhecida. É possível observar também que elas se relacionam com os principais stakeholders do projeto $(5,42)$, o que contribuir para que possam atingir as metas dos empreendimentos de uma forma geral. Observa-se, portanto, que os membros da amostra estão bastante envolvidos com a interface do grupo com a organização e demais stackholders do projeto, ou seja, coma interface externa, (Thamhaim, 1993).

No entanto, destaca-se que os aspectos internos às equipes são menos importantes, uma vez que existem dificuldades em resolver os problemas individuais $(4,72)$ e, também, que os conflitos durante o desenvolvimento do projeto nem sempre são moderados e fáceis de serem resolvidos $(4,87)$.

Ainda considerando-se os indicadores pessoais, nota-se que os aspectos ligados ao autodesenvolvimento da equipe, sua habilidade de comunicação e a confiança mutua entre seus membros, foram indicadores avaliados próximos do grau 5. Estes aspectos, muito enfatizados por diversos autores (Frame, 1999; Shtub et al, 1994; PMBoK,2000), aparecem em situação intermediária, entre a interface externa mais valorizada e os aspectos internos.

\section{Maturidade da Organização}

Os resultados obtidos permitiram distinguir alguns aspectos relacionados às competências das organizações no gerenciamento de projetos segundo o modelo de maturidade de Kerzner (2000). As principais características enfatizadas pelos entrevistados da amostra referem-se ao reconhecimento da importância do gerenciamento de projetos para a empresa (tanto pela alta administração como pela gerência), visibilidade em termos de suporte; e postura favorável quanto à mudança, conforme mencionado anteriormente. Não obstante, as características da fase de crescimento e maturidade foram às menos verificadas, como a preocupação ainda preliminar com o desenvolvimento de uma metodologia de gestão de projetos e pouco comprometimento com as atividades de planejamento sistema formal de controle, em especial custo e prazo (4,61 e 4,77). Destaca-se ainda a baixa preocupação com o autodesenvolvimento e capacitação com o intuito de aumentar as competências em gerenciamento de projetos na empresa.

Desta forma acredita-se que as organizações a que pertencem os membros da amostra estão em localizadas entre as fases de "reconhecimento da alta administração" e de "reconhecimento gerência", conforme ilustra a Figura 2.

\section{CONCLusões}

Tradicionalmente as empresas operam através de um aprofundamento técnico muito grande, muitas vezes deixando os aspectos gerenciais em segundo plano. Sabe-se hoje que o gerenciamento de projetos quando aplicado em sua plenitude deve valorizar em muito os aspectos gerenciais.

Um dos mais importantes aspectos percebidos no desenvolvimento de tarefas complexas refere-se as atitudes positivas em relação a formação de equipes de projetos.

Neste estudo foi possível analisar o caminho trilhado pelas organizações em busca da excelência em projetos, levando-se em consideração os aspectos ligados à construção de competências no âmbito das equipes de projetos e seus rebatimentos na organização. 
Em termos de competências das equipes de projetos foram analisados dois clusters de indicadores - tarefas e pessoas, balizados pelo ciclo de maturidade organizacional em projetos.

Os indicadores de tarefa e pessoas permitem evidenciar distorções entre os dois clusters bem como carências específicas em cada um dos grupos.

As primeiras conclusões verificadas foram que os indicadores mais fortemente percebidos, do lado pessoal, são aqueles que se referem à motivação da equipe em buscar resultados e o empenho em fazer interface externo com a corporação e os interessados (stakeholders) do projeto. Não obstante, os indicadores menos relevantes, do lado das tarefas, referem-se ao objetivo e resultado claro que o projeto deve atingir. A constatação que se faz muito evidente, quando se confrontam os indicadores de tarefa com os de caráter pessoal, é que, embora as equipes se motivem em buscar resultados elas não têm visibilidade dos objetivos e, portanto, a busca dos resultados torna-se ineficaz. Este descompasso compromete a motivação das equipes, bem como a eficácia dos projetos.

Por outro lado, foi possível notar que o indicador de tarefas referente ao gerenciamento de mudanças recebeu a maior avaliação, sendo que os conflitos e suas possibilidades de resolução, (do lado pessoal) foram avaliados com pouca e devida relevância. Cabe ao gerente de projetos, portanto, neste aspecto se preparar para enfrentar o gerenciamento de mudanças e suas clássicas implicações na reação de membros de equipes.

É possível notar, também, pelos resultados que as questões relativas à eficiência nos projetos não apresentaram bons desempenhos, em especial, em relação aos custos e prazos do projeto e na elaboração de tendências e cenários, o que mostra, segundo Kerzner (2000), que ainda não existe uma preocupação sistemática com o planejamento e controle, típicos das fases mais avançadas do modelo de maturidade. Aliado a este fato, destaca-se a tímida preocupação com a formação de competências em gestão de projetos e com o autodesenvolvimento, bem como a falta de integração interna, itens necessários para se atingir a maturidade.

A identificação das lacunas de percepção dos gerentes e membros de projetos pode ser uma ferramenta eficiente para o diagnóstico do estágio da gestão de projetos para corporação, orientando as ações de melhoria e a formulação de um programa de desenvolvimento visando atingir a fase de maturidade.

\section{Artigo recebido em 19/07/2001. Aprovado em 07/10/2002.}




\section{REFERÊNCIAS BIBLIOGRÁFICAS}

ARCHIBALD, R. D. Organizing the Project Office and Project Team: Duties of Project Participants IN: CLELAND, D. I.; KING, W, R. 1983 Project Management Handbook. Van Nostrand Reinhold, New York.

HAMEL, GARY \& PRAHALAD, C.K. 1995 Competindo Pelo Futuro: estratégias inovadoras para se obter o controle de seu setor e criar os mecanismos de amanhã, Rio de Janeiro, Ed. Campus.

CLELAND, D. I.; KING, W, R. 1983 Project Management Handbook. Van Nostrand Reinhold, New York.

FLEURY, A. \& FLEURY M.T.L. 2000. Estratégias Empresariais e Formação de Competências Um Quebra-cabeça Caleidoscópio da Indústria Brasileira, Ed. Atlas, São Paulo.

FRAME, J.D. , 1999 Project Management Competence: Building Key Skills for Individuals, Teams, and Organizations. Jossey-Bass Publishiers, San Francisco.

HARTMAN, F \& SKULMOSKI, G., 1999. Quest for Team Competence. Project Management, vol 5 n. 1.

INTERNATIONAL STANDARD ORGANIZATION. ISO 10006: Quality management Guidelines to quality in project management. s.l.p., ISO, 1997.

KERZNER, H. , 2000. Applied Project Management Best Practices on Implementation. John Wiley \& Sons, USA.

KING, W.R. , 1993 The Role of Projects in the Implementation of Business Strategy in: CLELAND, D.I. \& KING, W.R. Project Management Handbook. Van Nostrand Reinhold, New York.

PICQ, T. , 1999. Manager une Equipe Projet, Dunod, Paris.

PROJECT MANAGEMENT INSTITUTE - PMI. Guide of Project Management Body of Knowledge - PMBoK, 2000.

STEWART, T. A. , 1997 Capital Intelectual A Nova Vantagem Competitiva das Empresas, Editora Campus.

SHTUB,A. ; BARD, J. F. ; GLOBERSON, S. , 1994Project Management Engineering, Technology and Implementation, Prentice Hall, New Jersey.

THAMHAIN, H. J. , 1993. Team Building in Project Management in: CLELAND, D.I. \& KING, W.R. Project Management Handbook. Van Nostrand Reinhold, New York.

VERMA, VIJAY K. Managing the Project Team, PMI Project Management Institute, 1995. 